\title{
BMJ Open Development of a computerised decisions support system for renal risk drugs targeting primary healthcare
}

\author{
Anders Helldén, ${ }^{1,2}$ Fadiea Al-Aieshy, ${ }^{1}$ Pia Bastholm-Rahmner, ${ }^{2,3}$ Ulf Bergman, ${ }^{1,2}$ \\ Lars L Gustafsson, ${ }^{1,2}$ Hans Höök, ${ }^{3}$ Susanne Sjöviker, ${ }^{3}$ Anders Söderström, ${ }^{4}$ \\ Ingegerd Odar-Cederlöf ${ }^{1,2}$
}

To cite: Helldén A, Al-Aieshy F, BastholmRahmner $\mathrm{P}$, et al. Development of a computerised decisions support system for renal risk drugs targeting primary healthcare. BMJ Open 2015;5:e006775. doi:10.1136/bmjopen-2014006775

- Prepublication history and additional material is available. To view please visit the journal (http://dx.doi.org/ 10.1136/bmjopen-2014006775).

Received 30 September 2014 Revised 2 June 2015 Accepted 15 June 2015

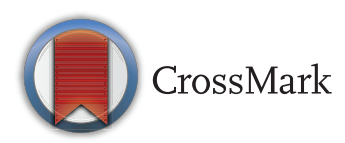

For numbered affiliations see end of article.

Correspondence to Dr Anders Helldén; anders.hellden@ki.se

\section{ABSTRACT}

Objectives: To assess general practitioners (GPs) experience from the implementation and use of a renal computerised decision support system (CDSS) for drug dosing, developed for primary healthcare, integrated into the patient's electronic health record (EHR), and building on estimation of the patient's creatinine clearance $\left(\mathrm{Cl}_{\mathrm{CG}}\right)$.

Design: Qualitative research design by a questionnaire and a focus group discussion.

Setting and participants: Eight GPs at two primary healthcare centres (PHCs).

Interventions: The GP at PHC 1, and the project group, developed and tested the technical solution of the CDSS. Proof-of-concept was tested by seven GPs at PHC 2. They also participated in a group discussion and answered a questionnaire. A web window in the EHR gave drug and dosage in relation to $\mathrm{Cl}_{\mathrm{CG}}$. Each advice was according to three principles: If? Why? Because.

Outcome measures: (1) The GPs' experience of 'easiness to use' and 'perceived usefulness' at PHC 2, based on loggings of use, answers from a questionnaire using a 5-point Likert scale, and answers from a focus group discussion. (2) The number of patients aged 65 years and older with an estimation of $\mathrm{Cl}_{\mathrm{CG}}$ before and after the implementation of the CDSS.

Results: The GPs found the CDSS fast, simple and easy to use. They appreciated the automatic presentation of the $\mathrm{Cl}_{\mathrm{CG}}$ status on opening the medication list, and the ability to actively look up specific drug recommendations in two steps. The CDSS scored high on the Likert scale. All GPs wanted to continue the use of the CDSS and to recommend it to others. The number of patients with an estimated $\mathrm{Cl}_{\mathrm{CG}}$ increased 1.6-fold.

Conclusions: Acceptance of the simple graphical interface of this push and pull renal CDSS was high among the primary care physicians evaluating this proof of concept. The graphical model should be useful for further development of renal decision support systems.

\section{INTRODUCTION}

Computerised decision support systems (CDSS) can help to achieve a more individualised and safe drug therapy when

\section{Strengths and limitations of this study}

- This study presents a renal computerised decision support system (CDSS) that provides easily available advice in short evidence-based texts, with explanations and references within reach for pharmacotherapy of patients with decreased renal function.

- According to questionnaire responses and a focus group discussion, the study showed that the GPs' appreciated the CDSS and found it easy to use and useful.

- This was a small-scale project, and larger tests in other settings would be useful.

integrated into the electronic health record (EHR). ${ }^{1}$ Knowledge about how CDSS applications for rational pharmacotherapy should be designed and tested to be able to provide proof-of-concept documentation has increased during the past years. ${ }^{1-4}$ However, a CDSS for drug dosing in patients with impaired renal function, and implemented in primary healthcare (PHC), was not present at the time when we initiated the development of our renal CDSS..$^{56}$

Decreased renal function is a well-known source for variability in drug response. ${ }^{7}$ Elderly patients may have decreased renal function due to physiological changes and due to age-related diseases, for example, atherosclerosis, heart failure and diabetes. ${ }^{8-10}$ The clinically used plasma (P-) creatinine is unreliable as a measure of renal function, particularly in the elderly. These patients may have reduced muscle mass with P-creatinine values within the reference range, even when creatinine clearance is below $50 \mathrm{~mL} / \mathrm{min}$, as shown in the study of digoxin. ${ }^{11}$ The renal clearance of drugs is usually correlated to the creatinine clearance, estimated as an absolute value in $\mathrm{mL} /$ min using different equations including the 
most established one, the Cockcroft \& Gault formula (here denoted by $\mathrm{Cl}_{\mathrm{CG}}$ ). ${ }^{12} 13$

The renal function is important for the choice of drugs and for optimal dosage of drugs with renally excreted parent drug and active metabolites. These may reach high or even toxic plasma concentrations with non-adjusted doses. ${ }^{1415}$ Estimation of renal function is a surrogate for renal drug clearance. Adequate dosages are best obtained by measuring plasma concentrations of the drug (Therapeutic Drug Monitoring). ${ }^{16} 17$

Inappropriate drug dosing may result in pharmacological adverse drug reactions (ADRs; type A), dosedependent and concentration-dependent, thus being predictable and theoretically preventable. ${ }^{6} 18{ }^{19}$ We and other researchers have shown that many ADRs in elderly patients are linked to low renal function and renal risk drugs, that is, drugs that should be avoided or are contraindicated, need dose adjustment, or are without effect in decreased renal function. ${ }^{20-22} \mathrm{~A}$ CDSS adapted to provide advice and guidance for selection and dosage of drugs in patients with decreased renal function has been lacking in Swedish PHC settings, ${ }^{1}{ }^{23}$ where the general practitioners (GPs) hardly have time to estimate $\mathrm{Cl}_{\mathrm{CG}}$. The aim of the study was to describe the key elements of the design and graphical interface of a renal CDSS, and to evaluate the acceptance of this interface by the primary care physicians at two PHCs in Stockholm.

\section{METHODS AND PATIENTS}

Our CDSS application, called 'The renal button' in this pilot, was developed over a period several years with the aim of giving rapid recommendations on the adaption of medication to renal function from the patient's EHR. We initiated the development as part of building the electronic infrastructure for 'Rational Use of Medicines in Stockholm'. ${ }^{2}$ From this project, we have experience of CDSS in the Swedish 'Janus' decision support system, ${ }^{24}$ including drug-drug interactions control. ${ }^{25}$ Our renal CDSS was integrated into the Janus web solution in the EHR to get rapid and reliable advice on the choice of drugs and dosages. ${ }^{24}$

\section{Steering committee}

The CDSS project was supervised by a steering committee with participation, for example, from the GP at the first PHC, from the Department of Clinical Pharmacology, Karolinska University Hospital, and from the Stockholm County Council. A medically responsible physician from the latter group could stop the project if it was deemed unsafe for the patients.

\section{The development}

The development of the CDSS followed two steps: establishment of the concept and proof of concept (figure 1).

The development was based on four interlinked approaches: a-d

a. Estimation of renal function and dosing of drugs

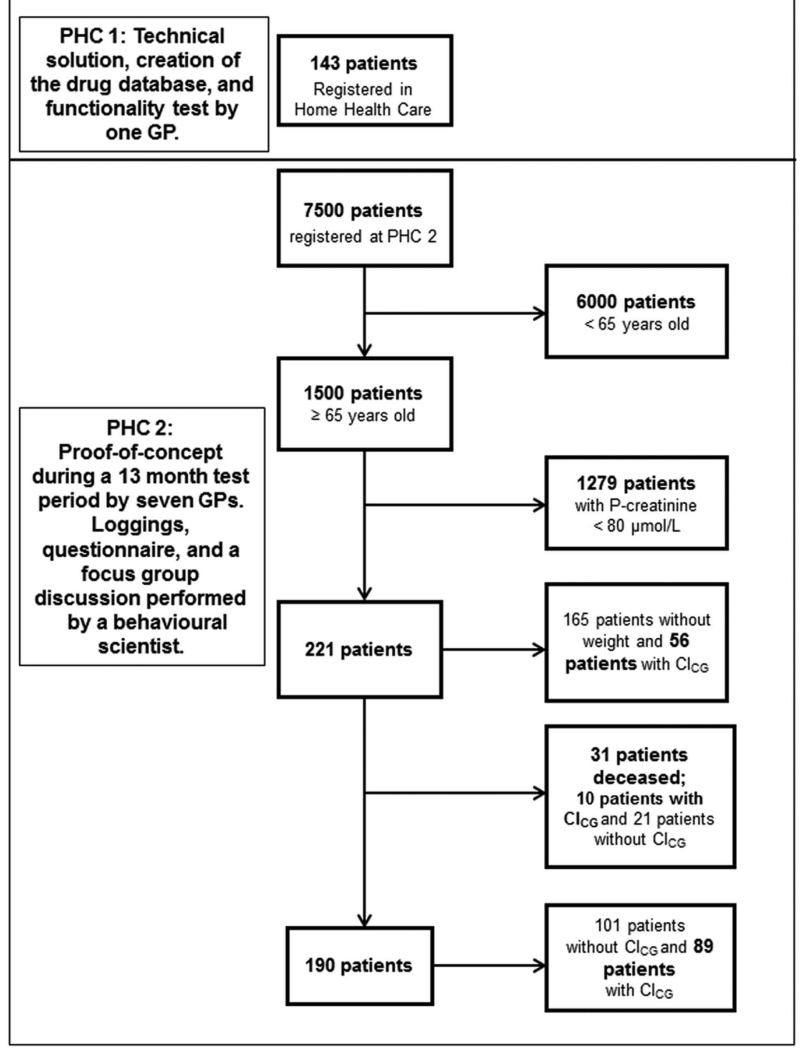

Figure 1 Flow chart of the study at the two primary healthcare centres (PHCs) and the change in the number of patients with an estimated creatinine clearance according to the Cockcroft \& Gault formula before and after the introduction of the renal computerised decision support system at PHC 2.

The renal function of the participating patients was calculated by an automatic estimation of $\mathrm{Cl}_{\mathrm{CG}}$ using individual patient data on body weight, age, sex and P-creatinine extracted from patient information in the EHR. ${ }^{12}$ The P-creatinine was recalculated from a modified Jaffe method, standardised to isotope-dilution mass spectrometry (IDMS), to uncompensated P-creatinine.

The $\mathrm{Cl}_{\mathrm{CG}}$ result was visualised with an image of a kidney in three different colours according to the $\mathrm{Cl}_{\mathrm{CG}}$ value (figure $2 \mathrm{~A}$ ). Advice on how $\mathrm{Cl}_{\mathrm{CG}}$ should be used as support for individualised pharmacotherapy is shown (figure 2B). Each advice for selection and dosage was according to three principles:

1. If? Is the drug suitable at all, and in what dosage?

2. Why? What are the risks of not individualising the doses according to renal function?

3. Because: Short text explaining the recommendations, and including references.

When entering the list of prescribed drugs in the patient's EHR, the physician got an automatic alert from the Janus web-based system starting with general guidelines, for example, in a patient with a $\mathrm{Cl}_{\mathrm{CG}}$ of $34 \mathrm{~mL} /$ min: "The patient has moderate renal failure. Dose reduction should be considered for the following drugs": (figure 2B). 

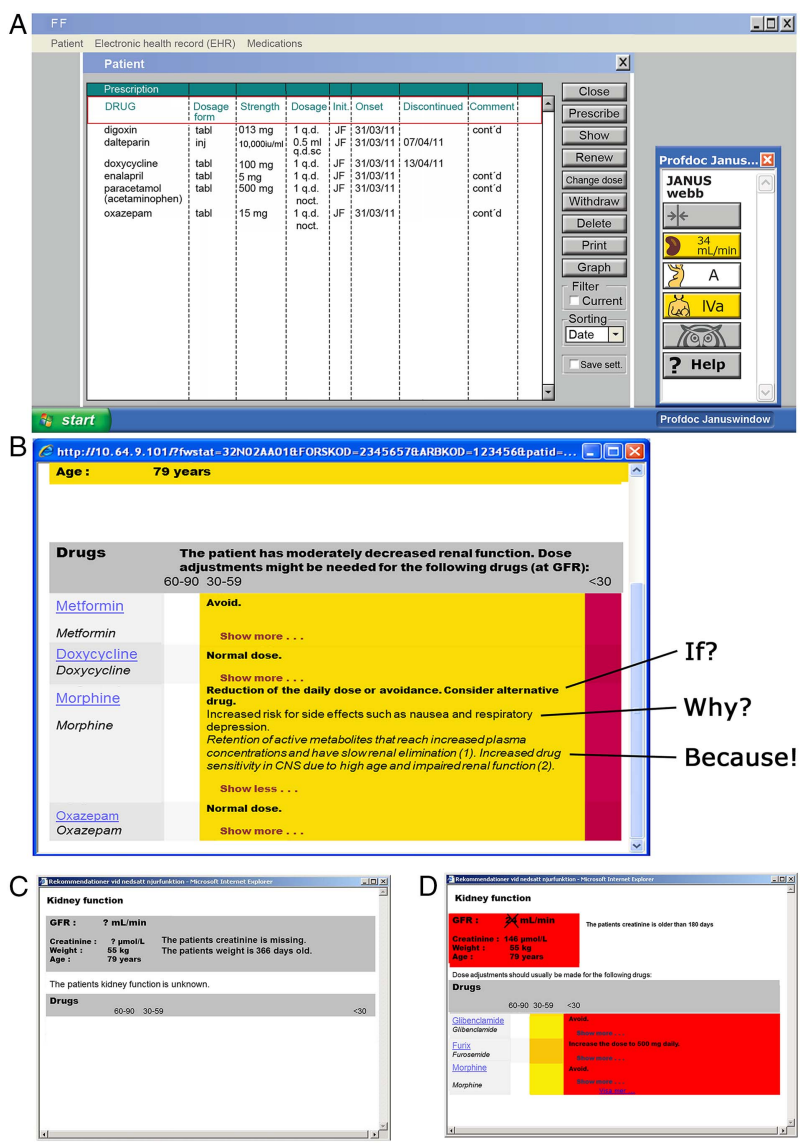

Figure 2 (A-D An elderly woman's list of medications integrated into the Janus window. When the general practitioner (GP) opens the medication list, the 'renal button' appears automatically in the Janus tool bar (A) (push level). Shown are also the buttons for drugs recommended in pregnancy, and in breastfeeding. The owl is a symbol for 'the wise list' of basic recommended drugs in Stockholm. ${ }^{3}$ The degree of renal function is presented in a colour code (white, yellow and red) according to the cut-off points of renal function. The GP must then decide to click the 'renal button' (pull level) and is presented with a selection of drugs on the medication list, for which dosing adjustment might be needed. Four drugs are shown: metformin, doxycycline, morphine and oxazepam. For each of these drugs, a short recommendation is given ("If") automatically after the first click (B). An additional click ("Show more") is required to visualise each of the following short texts ("Why" or "Because"). The "Because" text also includes two references (1 and 2), but could not be shown in this figure. ${ }^{6566}$ In case information is missing, clicking the grey colour 'renal button' will display an alert, indicating which information is missing (C), or outdated (D) and indicating which drugs might be affected in case the information was available, with need for dose adjustments. GFR=creatinine clearance estimated according to the equation of Cockcroft \& Gault, absolute values in $\mathrm{mL} / \mathrm{min}$.

\section{b. Evidence-based short texts}

The texts on selection and adjustment of doses according to the patient's renal function were short and based on classical information. The primary source of information was the systematic list of short advice on drug dosage at decreased renal function from the 1990 s to 2002 , created by IO-C, and widely used by Swedish physicians and medical students. ${ }^{26}$ The information was retrieved from early literature on renal failure and drug dosage, such as by the pioneer Dettli, ${ }^{14}$ guidance by Bennett in separate articles, in lists with comments, for example, in Avery's Drug Treatment, with the addition of modern standard work on pharmacokinetics by, for example, Aronoff $e t a l^{27}$ from our database literature research system, ${ }^{28}$ and from knowledge of drug pharmacokinetics and pharmacodynamics. The procedure was standardised with a fixed protocol using available literature and being critically analysed for each medication, giving the recommended dosages at normal and reduced renal function in per cent of normal dosage, prolonged dosage interval or both. ${ }^{14} 26 \quad 27 \quad 29$ When needed, information was retrieved from Summary of Product Characteristics (SPC), available at the Swedish Medical Products Agency (http://www.mpa.se) or European Medical Agency (http://www.ema.europa.eu) ${ }^{30}$ from systematic literature searches, or from evaluations in the question/answer database 'Drugline' (http://www.drugline.se). ${ }^{28} \quad 31$ Clinical experience was considered, making guidance relevant for a busy clinician.

The GP at the first PHC suggested drugs, frequently used at the PHC, to be added to the CDSS database ( $\mathrm{N}=166)$ (see online Supplement 1).

c. Technical solution and software integration

The development and installation of the renal CDSS was carried out in 2005-2006 at a PHC in a multidisciplinary collaboration to assure that the decision support was user-adapted and fulfilled aspects related to 'usefulness' and 'perceived easiness to use'. ${ }^{32-34}$ The collaboration was with the software company ProfDoc, being the dominating EHR in PHCs in Sweden around 2005 to $2008 .^{35}$

The renal CDSS was designed as a graphical interface in the Janus web window, which is embedded in the EHR (figure 2A). The technical structure was built on earlier implementations of CDSS in the Janus window. The renal support differed from earlier functions by requesting some additional data from the module of laboratory data in the EHR, such as the list of drugs, the patient's age, sex, weight and P-creatinine. Thereby, patient-specific drug dosing advice was made possible on the $\mathrm{Cl}_{\mathrm{CG}}$ formula. The result was presented to the prescriber in the Janus window (push level) only if all parameters within a certain time interval were available. If not so, we included a grey colour code of the alert indicating that there is no $\mathrm{Cl}_{\mathrm{CG}}$ available. When clicking this field, the CDSS informs that body weight and/or P-creatinine are missing, or older than the preset time (figure 2C, D). If a patient's drug was not in the database, an alert appeared saying that the GP should see the SPC, or the Physician's Desk Reference (PDR).

d. Evaluation of the concept in clinical practice

1. Test of acceptance by prescribing physicians: The first model of the CDSS was tested among home healthcare patients registered at the first PHC. The GP at this PHC participated in the development of the 
CDSS, suggested improvements, and recommended additional drugs that he wanted to include information about. This evaluation was also a functionality test including an oral report of how the CDSS worked.

2. Test of proof-of-concept: Proof-of-concept was thereafter performed at the second PHC in Stockholm, with a catchment area of 7500 inhabitants. All seven physicians at the centre participated. The project started with a baseline study performed as a pharmacy student project, 8 months before the introduction of the CDSS. A total of 221 patients, 65 years and older, with a P-creatinine above $80 \mu \mathrm{mol} / \mathrm{L}$, were included. Patients who could be weighed, and thus have their $\mathrm{Cl}_{\mathrm{CG}}$ estimated, were followed during 1213 months in 2007-2008. We also compared $\mathrm{Cl}_{\mathrm{CG}}$ between men and women.

\section{Methods for evaluation of use and usefulness of the CDSS}

Three different methods were used to be able to evaluate the actual use and physicians' attitudes and perceptions of the CDSS: (1) log files, (2) a questionnaire and (3) group discussion.

1. Log files: The evaluation included analysis of a register of $\log$ files to see how often and with which parts the CDSS was used. Logged parameters recorded referral to any of the three different levels in the CDSS: the pull for the 'If' level, for the 'Why' level and for the 'Because' level. Loggings were registered anonymously.

2. Questionnaire: The physicians answered an anonymous questionnaire on their experience of the CDSS. Data from the questionnaires were summarised descriptively.

3. Group discussion: All physicians took part in a focus group discussion (FGD). This was used to explore the perceived usefulness of the CDSS and in what way the system can help physicians to improve the quality of drug therapy. We chose this data collection method because group discussions are valuable in examining how people think and how ideas operate within a given cultural context. ${ }^{36}$ The FGD started broadly with questions related to the use of the CDSS. Thereafter, the FGD continued by asking more specific questions about the physicians' perceived usefulness of the CDSS (table 1).

The discussion lasted for about $45 \mathrm{~min}$ and was audio recorded and transcribed verbatim. The transcribed texts were analysed stepwise according to an inductive thematic analysis without any prior given categories. ${ }^{37}$

The primary outcomes were as follows:

1. The GPs' experience of 'easiness to use' and 'perceived usefulness', according to loggings, a questionnaire and a FGD.

2. The number of patients 65 years and older with an estimation of $\mathrm{Cl}_{\mathrm{CG}}$ before and after the implementation of the CDSS.

\begin{tabular}{|c|c|}
\hline $\begin{array}{l}\text { Introductory } \\
\text { question } \\
\text { Transition } \\
\text { questions }\end{array}$ & $\begin{array}{l}\text { What is your overall perception of the } \\
\text { CDSS? } \\
\text { In which situations do you as a } \\
\text { prescriber have use/no use of the } \\
\text { provided information by the renal } \\
\text { button? }\end{array}$ \\
\hline Key questions & $\begin{array}{l}\text { Does the service provide the } \\
\text { information you ask for? } \\
\text { What decides the usefulness of the } \\
\text { application? } \\
\text { Have your decisions and thinking } \\
\text { around medication treatment } \\
\text { changed with the use of the } \\
\text { service? } \\
\text { Has your patient work been } \\
\text { changed when working with this } \\
\text { service? }\end{array}$ \\
\hline
\end{tabular}

\section{Statistics}

$\mathrm{Cl}_{\mathrm{CG}}$ is presented as mean $\pm \mathrm{SD}$. Student $\mathrm{t}$ test was used for comparison of ordinal data. $\mathrm{P}<0.05$ was regarded as significant. Statistics was calculated by Statistica, V.10, (Statsoft Inc, Tulsa, Oklahoma, USA).

\section{RESULTS}

\section{Establishment of the concept}

The GP at the first PHC found it positive with automatic access to renal function information and advice on dosages at the point of care. At the end of the development, the GP appreciated that the advice was short and visual and that the service was prompt and easy to use. The GP used the CDSS for 143 patients, of whom 123 were more than 65 years old (mean age 81.4 years, range 65-96), could be weighed and were not in terminal condition.

In 113 patients $(92 \%)$, the $\mathrm{Cl}_{\mathrm{CG}}$ was below $60 \mathrm{~mL} / \mathrm{min}$ (mean and SD); $38.1 \pm 10.8 \mathrm{~mL} / \mathrm{min}$.

\section{Proof of concept}

All seven GPs at the second PHC took part in the pilot project.

1. The following results were retrieved from logged files

- During the test, the seven physicians used the information at level 1 ("If?") 446 times.

- On 53 occasions (12\%), more information was looked for at level 2 ("Why?").

- On 30 occasions (7\%) more information was looked for at level 3 ("Because").

As a comparison, 30 loggings were carried out to the support system of 'Interactions', and on eight occasions to the 'Adverse drug reactions' CDSS system in the Janus window. 


\section{Questionnaire}

All seven physicians wanted to continue using the renal support in the future, and all found it valuable and wanted to recommend it to other colleagues (table 2).

\section{The FGD}

In the FGD, the seven physicians expressed that the interest to adjust medication to the patient's renal function increased after the test period. They were in agreement that the collected drug information in the Janus window led to more individual medications and dosages than earlier. Changes of doses or drugs were considered if the renal colour button had turned yellow or red. Signs and symptoms and treatment were also evaluated. The possibility to test if a specific drug was suitable for the patient by a test prescription was appreciated.

The physicians used the CDSS as a source of information and strengthening their own knowledge, but not as a pedagogic tool in their work with the patients. The positive comments were about simplicity, speed and possibilities of choice. Individual statements about the use, value of and attitudes to the CDSS are summarised in box 1 .

\section{Renal function assessments at the second PHC}

A total of 221 patients aged 65 years and older had a P-creatinine above $80 \mu \mathrm{mol} / \mathrm{L}$ (15\% of all patients). Thirty-one of these patients had died during the study period. $\mathrm{Cl}_{\mathrm{CG}}$ could eventually be estimated in $89(47 \%)$ of the remaining 190 patients and was $42.7 \pm 15.1 \mathrm{~mL} / \mathrm{min}$. It differed between women and men and was $35.7 \pm 8.9 \mathrm{~mL} /$ $\mathrm{min}$ and $47.4 \pm 16.6 \mathrm{~mL} / \mathrm{min}$, respectively $(\mathrm{p}<0.001)$, while P-creatinine did not differ significantly $(123 \pm 23 \mu \mathrm{mol} / \mathrm{L}$ and $132 \pm 34 \mu \mathrm{mol} / \mathrm{L}$, respectively, $\mathrm{p}=0.14)$. Seventy-seven patients (87\%; mean age 82.7 years, range 68-96) had $\mathrm{Cl}_{\mathrm{CG}}$ below $60 \mathrm{~mL} / \mathrm{min}$, with 17 of these less than $30 \mathrm{~mL} / \mathrm{min}$.

\section{DISCUSSION}

The results from this concept study showed that technology enables delivery of useful hands-on information on renal function and on drug treatment in the elderly in a fast and easy way. ${ }^{23}$ Such a type of tool has the potential to increase the adequacy of drug treatment, ${ }^{38}$ decrease the risk of pharmacological ADRs (type A), and contribute to protecting the renal function. ${ }^{5}$

It was well established that Swedish physicians wished for a CDSS for renal function. ${ }^{39}$ The GPs reported that time with the patients was mostly too short to estimate the renal function and to find appropriate recommendations on how to adjust drug treatment. Using the Swedish PDR provided limited, and sometimes inconsistent, information. ${ }^{40}$

One of the strengths of our CDSS was that the recommendations were given at the point of care. The system had flexibility with short recommendation texts in accordance with wishes from the GPs (figure 2B). Only the attending physician with full knowledge about the patient, disease, clinical situation and treatment schedule can adjust pharmacotherapy according to these factors. In evaluations of CDSS in general, the users underline that the information must be short and clear. $^{32325}$

The number of participating patients and physicians in our study may seem small, but evaluations of small-scale projects are important tools in the design of an optimal intervention of CDSS that improves healthcare quality. There is a risk that resources are spoiled without such concept studies.

Small-scale projects can thus provide the basis for the further development and broader implementation of pharmacological electronic tools and services. ${ }^{24} 38$

Table 2 Questionnaire to seven general practitioners who used the renal button during 13 months at most

\begin{tabular}{|c|c|c|c|c|c|}
\hline & $\begin{array}{l}\text { Once a } \\
\text { week }\end{array}$ & $\begin{array}{l}\text { Two to five } \\
\text { times a week }\end{array}$ & $\begin{array}{l}\text { One to two } \\
\text { times a day }\end{array}$ & $\begin{array}{l}\text { More than } 2 \\
\text { times a day }\end{array}$ & \\
\hline \multirow[t]{2}{*}{ I use the renal button: } & 3 & 2 & 1 & 1 & \\
\hline & Not at all* & A little & Moderately & Rather much & Much \\
\hline Is the renal button of help in everyday work? & 0 & 0 & 1 & 4 & 2 \\
\hline $\begin{array}{l}\text { Has the renal button influenced your choice of } \\
\text { medication? }\end{array}$ & 0 & 0 & 5 & 2 & 0 \\
\hline $\begin{array}{l}\text { Do you think that the renal button has contributed to } \\
\text { reducing dose-dependent ADRs in your patients? }\end{array}$ & 0 & 1 & 1 & 4 & 0 \\
\hline Has the renal button contributed to under-treatment? & 3 & 2 & 0 & 2 & 0 \\
\hline $\begin{array}{l}\text { Has the renal button led to extra advantages such as } \\
\text { information on body weight and present (current) } \\
\text { P-creatinine? }\end{array}$ & 1 & 2 & 1 & 0 & 3 \\
\hline Is the renal button time-consuming and/or overloading? & 6 & 1 & 0 & 0 & 0 \\
\hline \multirow[t]{2}{*}{ Has the renal button led to disadvantages? } & 5 & 2 & 0 & 0 & 0 \\
\hline & Yes & No & & & \\
\hline Do you want to continue using the renal button? & 7 & 0 & & & \\
\hline Can you recommend the renal button to colleagues? & 7 & 0 & & & \\
\hline
\end{tabular}

${ }^{*}$ Numbers of answers on the Likert scale (minimum 1 and maximum 5).

ADRs, adverse drug reactions. 
Box 1 Quotations from seven physicians at the focus group discussion about the usage of, value of and attitudes to the renal support at the second primary healthcare centre

- The individual adjustments of dosages were used in greater extent since the GFR value was given automatically and together with advice on dosages.

- Old knowledge became more available with the new technique. The renal button and the interaction service had reciprocal positive effects on each other.

- The "renal button" gave a certain amount of more work, but it was positive because it facilitated the judgment, medication, and increased safety.

- You read, correct, and work more preventively, and avoid dangerous situations that could have meant admission to hospital.

- It should be simple and clear. You should know at once what to use the information for and what you should do. I think these demands are well filled up with this function. This is information that we simply did not have earlier.

- The advice should not be directive but give attention so that they facilitate your own judgment.

- The colour marking should remain also after the dose adjustment in order to mark out the patient's renal function.

- It is a shortcoming that APO-doses (pre-dispensed medication) are not integrated into the EHR computer record.

Our CDSS became a feedback system where decreased renal function of various degrees was visualised and became a patient-specific prescriber and decision support with embedded guidelines, essential to achieve good adherence to recommendations and ensure 'easiness of use'. ${ }^{1-42}$ A visual format is well appreciated with high adherence to recommendations by busy clinicians. $^{38}$

A weakness of our CDSS was that a completely developed system demands that $\mathrm{Cl}_{\mathrm{CG}}$ can be documented in the EHR. This function was not possible in this pilot version. The EHR product was a closed source proprietary product. However, the technical capabilities of the CDSS functions could be much improved by open interface or open source software.

Another weakness was that we had no evaluation of the effects on the prescribing, but this had been carried out earlier, for example, in a study from $2001 .{ }^{5}$ The prescribers using our CDSS were not provided with an alternative recommendation, but they could 'test' alternative medications. In addition, the prescriber always had the possibility to contact us and ask drug-related questions at our Drug Information Center. ${ }^{28} 31$

CDSS using intervention groups and control groups have also been studied for patients with renal impairment in long-term care, and in an emergency department. The CDSS improved the prescriptions in the intervention groups in both studies. ${ }^{41} 42$

In a review of clinical trials of CDSS, it was found that those which automatically prompted users to action improved the prescribers' performance. ${ }^{43}$ In contrast, in our study the prescriber could choose to either use the
CDSS or not, and preferred advice that was not demanding but that gave a reminder about renal function in pharmacotherapy.

There are few studies in primary care on the uptake and use of CDSS. In a multifaceted intervention, the software 'DOSING' could not be linked directly to the practices EHR because of incompatibility. ${ }^{44}$ In another study, estimated-glomerular filtration rate (eGFR) below $40 \mathrm{~mL} / \mathrm{min} / 1.73 \mathrm{~m}^{2}$ was reported to the pharmacist, who suggested appropriate medication to the physician. ${ }^{45}$ In contrast, our CDSS gave detailed recommendations in various degrees of renal impairment to GPs, reachable via the Janus web. ${ }^{24}$

In several studies, there were over-rides. The main reason $(68 \%)$ was 'that the patient has tolerated this drug in the past'. ${ }^{46}$ The results demonstrate the need to design CDSSs that are easy to use, pedagogic and with concise information.

A study of GPs in UK, including video filming, showed that the GP experienced several alerts, for example, on potential allergies and intolerance. ${ }^{4}$ Frequent alerts at the end of the consultation process may be unwelcome or disturbing and alert fatigue may follow. CDSS alerts should be reduced and follow the work flow of the patient's visit.

A Finnish-Swedish CDSS (Renbase) was used as expert recommendations in a recent Danish observational study. ${ }^{47}$ This CDSS is used in EHRs at certain hospitals and PHCs in Sweden. ${ }^{49}$ The texts are longer than in our CDSS. ${ }^{50} 51$

It is debatable which equation of estimation of renal function should be used when prescribing drugs, and if it should be based on creatinine, cystatin $\mathrm{C}$ or both. ${ }^{52-55}$ We used the $\mathrm{CL}_{\mathrm{CG}}$ estimation of creatinine clearance, in accordance with recommendations from the Swedish PDR, and from the Food and Drug Administration (FDA) in the USA. ${ }^{13}$ The $\mathrm{Cl}_{\mathrm{CG}}$ was used in most of the CDSSs on renal failure. ${ }^{44}$ Other equations, such as the Modification of Diet in Renal Disease (MDRD) and the Chronic Kidney Disease Epidemiology Collaboration (CKD-Epi) equations (eGFR presented in relative values $\left.\left(\mathrm{mL} / \mathrm{min} / 1.73 \mathrm{~m}^{2}\right)\right)$, have been suggested for estimation of renal function, partly because the patient's weight is not required. In our study, the patient's weight for the $\mathrm{Cl}_{\mathrm{CG}}$ equation was missing in many cases at the beginning. However, significantly more patients had been weighed after 8 months, as an additional advantage also for patients with, for example, diabetes, heart failure and suspected malignancies. Our experience is that the $\mathrm{Cl}_{\mathrm{CG}}$ formula is more accurate in elderly patients without renal impairment with low muscle mass, and subsequently low P-creatinine values. The estimation will result in low $\mathrm{Cl}_{\mathrm{CG}}$, while other formulas will result in high eGFRs and consequently a high dose. ${ }^{56-60}$ This is important, particularly in hospitalised elderly patients. $^{6162}$ Earlier, we found that these relative eGFR values may result in higher doses of dabigatran, valacyclovir and gabapentin, which may increase the risk for 
ADRs, particularly in elderly women. ${ }^{63}$ Similar results were obtained in a large study of patients with atrial fibrillation $(\mathrm{AF})$ treated with new oral anticoagulants. ${ }^{64}$

We have more than 10 years' experience in integrating different CDSSs into various EHR systems, the drugdrug interaction database SFINX, introducing drug recommendations in pregnancy, and in breastfeeding. ${ }^{25}$ The renal CDSS is a further step forward. The renal service was more complicated and therefore demanded a clear structure, a simple interface and concise advice presented in a visual way. This is in line with findings in decision-making in intensive care, using visualisation of recommendations with a high rating of performance and preferences. ${ }^{38}$ Our concept was developed to be present early in the decision process by being integrated in a patient-doctor joint display screen, which would actively involve the patient in the drug treatment. Our renal CDSS may become a prototype for similar prescribing systems. However, it is essential to create a standard for the most accurate algorithm for estimation of the renal function that should be used. ${ }^{4}$ The algorithm should be easily understandable in order to get acceptance among the prescribers, particularly among the growing elderly population. In our two PHC populations with a mean age of 80 years, about $90 \%$ had CL $_{\mathrm{CG}}$ below $60 \mathrm{~mL} / \mathrm{min}$. This is a level of concern for drug prescribing. A further step would be to incorporate the results from therapeutic drug monitoring, and use these data into an improved renal CDSS.

\section{CONCLUSION}

The development of our renal CDSS, embedded in the EHR, showed that close collaboration between GPs, a pharmacy student, a research nurse, a behavioural scientist, software developers, nephrologists and clinical pharmacologists resulted in a CDSS with focus on simplicity and visually presented advice. The system aimed to give support to GPs in reaching treatment and, adapt well to renal function, with the lowest possible risk for ADRs. These experiences suggest that the CDSS would be useful in PHCs, particularly in elderly women, where decreased renal function is prevalent and often overlooked. Our model may also be useful for other similar CDSSs.

\author{
Author affiliations \\ ${ }^{1}$ Department of Clinical Pharmacology, Karolinska University Hospital, \\ Stockholm, Sweden \\ ${ }^{2}$ Division of Clinical Pharmacology, Department of Laboratory Medicine, \\ Karolinska Institutet, Stockholm, Sweden \\ ${ }^{3}$ Department of Healthcare Development, Public Healthcare Administration, \\ Stockholm County Council, Stockholm, Sweden \\ ${ }^{4}$ Vendelsö Healthcare Centre, Stockholm, Sweden
}

Acknowledgements This study was possible due to the efforts of several employees at Farsta Homecare Centre, at Liseberg Primary Healthcare Centre, the software company ProfDoc, and at the Department of Drug Management and Informatics at Stockholm Healthcare Region over a period of several years. The authors also acknowledge the support from project manager Lennart Jacobsson.

Contributors AH, IO-C, LLG and UB initiated the project. AH, UB and IO-C designed the initial parts and participated during the whole project. IO-C developed the drug data base and $\mathrm{HH}$ developed the main software. AS was the first tester, and he contributed in the further development of the CDSS at the first PHC. SS was the project manager at the Stockholm County Council, and she contributed in the collection of data at both PHCs. FA-A collected the data for the retrospective study and performed the prospective study at the second PHC, in collaboration with SS. LLG advised on how to organise and structure the drug database and, together with I0-C, was responsible for the design and text in the first version of the manuscript. PB-R and SS were responsible for the questionnaire and the Focus Group Discussion, and for the interpretation of the results, at the second PHC. All authors contributed to the decisions about how to present the data, as well as organise and edit the final manuscript.

Funding This study was partly supported by the Stockholm Healthcare Region and by funds from Karolinska Institutet.

Competing interests None declared.

Ethics approval This development work was regarded as a quality project. Therefore, it was not considered necessary to get approval from a human research ethics committee. The design and the plans were approved by the executive directors of the involved PHCs. All respondents were informed that they were free to abstain from participation in any part of this quality work.

Provenance and peer review Not commissioned; externally peer reviewed.

Data sharing statement All data are included in the manuscript or online appendices.

Open Access This is an Open Access article distributed in accordance with the Creative Commons Attribution Non Commercial (CC BY-NC 4.0) license, which permits others to distribute, remix, adapt, build upon this work noncommercially, and license their derivative works on different terms, provided the original work is properly cited and the use is non-commercial. See: http:// creativecommons.org/licenses/by-nc/4.0/

\section{REFERENCES}

1. Eiermann B, Bastholm-Rahmner P, Korkmaz S, et al. Knowledge databases for clinical decision support in drug prescribingdevelopment, quality assurance, management, integration, implementation and evaluation of clinical value. In: Chiang SJ, ed. Clinical decision support. Vienna: INTECH, 2010:139-64.

2. Sjöborg B, Bäckström T, Arvidsson LB, et al. Design and implementation of a point-of-care computerized system for drug therapy in Stockholm metropolitan health region-bridging the gap between knowledge and practice. Int $J$ Med Inform 2007;76:497-506.

3. Gustafsson LL, Wettermark B, Godman B, et al. The 'wise list'-a comprehensive concept to select, communicate and achieve adherence to recommendations of essential drugs in ambulatory care in Stockholm. Basic Clin Pharmacol Toxicol 2011;108:224-33.

4. Hayward J, Thomson F, Milne $\mathrm{H}$, et al. 'Too much, too late': mixed methods multi-channel video recording study of computerized decision support systems and GP prescribing. J Am Med Inform Assoc 2013;20:e76-84.

5. Chertow GM, Lee J, Kuperman GJ, et al. Guided medication dosing for inpatients with renal insufficiency. JAMA 2001;286:2839-44.

6. Tawadrous D, Shariff SZ, Haynes RB, et al. Use of clinical decision support systems for kidney-related drug prescribing: a systematic review. Am J Kidney Dis 2011;58:903-14.

7. Reidenberg MM, Odar-Cederlöf I, von Bahr C, et al. Protein binding of diphenylhydantoin and desmethylimipramine in plasma from patients with poor renal function. N Engl J Med 1971;285:264-7.

8. Granerus G, Aurell M. Reference values for 51Cr-EDTA clearance as a measure of glomerular filtration rate. Scand J Clin Lab Invest 1981;41:611-16.

9. Mühlberg W, Platt D. Age-dependent changes of the kidneys: pharmacological implications. Gerontology 1999;45:243-53.

10. Fehrman-Ekholm I, Skeppholm L. Renal function in the elderly ( $>70$ years old) measured by means of iohexol clearance, serum creatinine, serum urea and estimated clearance. Scand J Urol Nephrol 2004;38:73-7. 
11. Piergies AA, Worwag EM, Atkinson AJ. A concurrent audit of high digoxin plasma levels. Clin Pharmacol Ther 1994;55:353-8.

12. Cockcroft DW, Gault MH. Prediction of creatinine clearance from serum creatinine. Nephron 1976;16:31-41.

13. Food and Drug Administration. Guidance for Industry Pharmacokinetics in Patients with Impaired Renal Function-Study Design, Data Analysis, and Impact on Dosing and Labeling. 1998. http://wwwfdagov/downloads/Drugs/GuidanceComplianceRegulatory Information/Guidances/ucm072127.pdf (accessed 2012-01-10).

14. Dettli L. Drug dosage in renal disese. Clin Pharmacokinet 1976;1:126-34.

15. Helldén A, Odar-Cederlöf I, Diener $P$, et al. High serum concentrations of the acyclovir main metabolite 9-carboxymethoxymethylguanine in renal failure patients with acyclovir-related neuropsychiatric side effects: an observational study. Nephrol Dial Transplant 2003;18:1135-41.

16. Duhme DW, Greenblatt DJ, Koch-Weser J. Reduction of digoxin toxicity associated with measurement of serum levels. A report from the Boston Collaborative Drug Surveillance Program. Ann Intern Med 1974;80:516-19.

17. Eliasson E, Lindh JD, Malmström RE, et al. Therapeutic drug monitoring for tomorrow. Eur J Clin Pharmacol 2013;69(Suppl 1):25-32.

18. Pirmohamed M, James S, Meakin S, et al. Adverse drug reactions as cause of admission to hospital: prospective analysis of 18820 patients. BMJ 2004;329:15-19.

19. Odar-Cederlöf I, Oskarsson P, Öhlén G, et al. [Adverse drug effect as cause of hospital admission. Common drugs are the major part according to the cross-sectional study]. (In Swedish) Läkartidningen 2008;105:890-3.

20. Corsonello A, Pedone C, Corica F, et al. Concealed rena insufficiency and adverse drug reactions in elderly hospitalized patients. Arch Intern Med 2005;165:790-5.

21. Blix HS, Viktil KK, Moger TA, et al. Use of renal risk drugs in hospitalized patients with impaired renal function-an underestimated problem? Nephrol Dial Transplant 2006;21:3164-71.

22. Helldén A, Bergman U, von Euler $M$, et al. Adverse drug reactions and impaired renal function in elderly patients admitted to the emergency department: a retrospective study. Drugs Aging 2009;26:595-606.

23. Rahmner PB, Eiermann B, Korkmaz S, et al. Physicians' reported needs of drug information at point of care in Sweden. Br J Clin Pharmacol 2012;73:115-25.

24. Eliasson M, Bastholm P, Forsberg $\mathrm{P}$, et al. Janus computerised prescribing system provides pharmacological knowledge at point of care-design, development and proof of concept. Eur J Clin Pharmacol 2006;62:251-8.

25. Böttiger $\mathrm{Y}$, Laine $\mathrm{K}$, Andersson ML, et al. SFINX-a drug-drug interaction database designed for clinical decision support systems. Eur J Clin Pharmacol 2009;65:627-33.

26. Odar-Cederlöf I. [Impaired renal function and drug treatment] (In Swedish) Läkemedelsboken 2001/2002. Stockholm: Apoteket AB, 2002:932-49.

27. Aronoff G, Bennett WM, Berns JS, et al. In: Aronoff G, ed. Drug prescribing in renal failure, 5 th edn. App D. Philadelphia: American College of Physicians, 2007.

28. Alván G, Andersson ML, Asplund AB, et al. The continuing challenge of providing drug information services to diminish the knowledge-practice gap in medical practice. Eur J Clin Pharmacol 2013;69(Suppl 1):65-72.

29. Bennett W. Guide to drug dosage in renal failure. In: Speight T, ed. Avery's drug treatment. App D. Auckland: Wiley-Blackwell, 1997:1726-56.

30. Maxwell S, Eichler HG, Bucsics A, et al. e-SPC-delivering drug information in the 21st century: developing new approaches to deliver drug information to prescribers. Br J Clin Pharmacol 2012;73:12-15.

31. Alván G, Öhman B, Sjöqvist F. Problem-oriented drug information: a clinical pharmacological service. Lancet 1983;2:1410-12.

32. Holden RJ, Karsh BT. The technology acceptance model: its past and its future in health care. J Biomed Inform 2010;43:159-72.

33. Kardakis T, Tomson G, Wettermark B, et al. The establishment and expansion of an innovative centre for rational pharmacotherapydeterminants and challenges. Int $J$ Health Plann Manage 2015;30:14-30.

34. Zakane SA, Gustafsson LL, Tomson G, et al. Guidelines for maternal and neonatal "point of care": needs of and attitudes towards a computerized clinical decision support system in rural Burkina Faso. Int J Med Inform 2014;83:459-69.

35. Kristianson KJ, Ljunggren $\mathrm{H}$, Gustafsson LL. Data extraction from a semi-structured electronic medical record system for outpatients: a model to facilitate the access and use of data for quality control and research. Health Informatics $J$ 2009:15:305-19.

36. Kitzinger J. Qualitative research. Introducing focus groups. BMJ 1995;311:299-302.

37. Patton M. Qualitative research \& evaluation methods. Thound Oaks, CA, USA: Sage, 2002.

38. Forsman J, Anani N, Eghdam A, et al. Integrated information visualization to support decision making for use of antibiotics in intensive care: design and usability evaluation. Inform Health Soc Care 2013;38:330-53.

39. Bastholm Rahmner P, Andersén-Karlsson E, Arnhjort T, et al. Physicians' perceptions of possibilities and obstacles prior to implementing a computerised drug prescribing support system. Int $J$ Health Care Qual Assur 2004;17:173-9.

40. Asker-Hagelberg C, Rydberg D, Hentschke M, et al. [Unclear on dose adjustment in renal impairment]. Läkartidningen 2013;110:1030-2.

41. Field TS, Rochon P, Lee M, et al. Computerized clinical decision support during medication ordering for long-term care residents with renal insufficiency. J Am Med Inform Assoc 2009;16:480-5.

42. Terrell KM, Perkins AJ, Hui SL, et al. Computerized decision support for medication dosing in renal insufficiency: a randomized, controlled trial. Ann Emerg Med 2010;56:623-9.

43. Garg AX, Adhikari NK, McDonald $\mathrm{H}$, et al. Effects of computerized clinical decision support systems on practitioner performance and patient outcomes: a systematic review. JAMA 2005;293:1223-38.

44. Erler A, Beyer M, Petersen JJ, et al. How to improve drug dosing for patients with renal impairment in primary care-a cluster-randomized controlled trial. BMC Fam Pract 2012;13:91.

45. Joosten $\mathrm{H}$, Drion I, Boogerd KJ, et al. Optimising drug prescribing and dispensing in subjects at risk for drug errors due to renal impairment: improving drug safety in primary healthcare by low eGFR alerts. BMJ Open 2013;3:e002068.

46. Cho I, Slight SP, Nanji KC, et al. Understanding responses to a renal dosing decision support system in primary care. Stud Health Technol Inform 2013;192:931.

47. Nielsen AL, Henriksen DP, Marinakis $\mathrm{C}$, et al. Drug dosing in patients with renal insufficiency in a hospital setting using electronic prescribing and automated reporting of estimated glomerular filtration rate. Basic Clin Pharmacol Toxicol 2013;114:407-13.

48. Renbase". http://www.medbase.fi/en/professionals/renbase (accessed 2014-08-11)

49. Cars T, Wettermark B, Malmström RE, et al. Extraction of electronic health record data in a hospital setting: comparison of automatic and semi-automatic methods using anti-TNF therapy as model. Basic Clin Pharmacol Toxicol 2013;112:392-400.

50. Wass S, Carlsson B, Vimarlund V, et al. Towards capturing innovation effects of a CDSS (NjuRen). Stud Health Technol Inform 2013;192:1049.

51. Shemeikka T, Bastholm-Rahmner P, Elinder CG, et al. A health record integrated clinical decision support system to support prescriptions of pharmaceutical drugs in patients with reduced renal function: design, development and proof of concept. Int J Med Inform 2015;84:387-95.

52. Spruill WJ, Wade WE, Cobb HH. Comparison of estimated glomerular filtration rate with estimated creatinine clearance in the dosing of drugs requiring adjustments in elderly patients with declining renal function. Am J Geriatr Pharmacother 2008;6:153-60.

53. Stevens L, Nolin T, Richardson M, et al. Comparison of drug dosing recommendations based on measured GFR and kidney function estimating equations. Am J Kidney Dis 2009;54:33-42.

54. Shlipak MG, Matsushita K, Ärnlöv J, et al. Cystatin C versus creatinine in determining risk based on kidney function. $N$ Engl $J$ Med 2013;369:932-43

55. Nyman U, Grubb A, Larsson A, et al. The revised Lund-Malmö GFR estimating equation outperforms MDRD and CKD-EPI across GFR, age and BMI intervals in a large Swedish population. Clin Chem Lab Med 2014;52:815-24

56. Wuyts B, Bernard D, Van den Noortgate N, et al. Reevaluation of formulas for predicting creatinine clearance in adults and children, using compensated creatinine methods. Clin Chem 2003;49:1011-14.

57. Melloni C, Peterson ED, Chen AY, et al. Cockcroft-Gault versus modification of diet in renal disease: importance of glomerular filtration rate formula for classification of chronic kidney disease in patients with non-ST-segment elevation acute coronary syndromes. J Am Coll Cardiol 2008;51:991-6.

58. Golik MV, Lawrence KR. Comparison of dosing recommendations for antimicrobial drugs based on two methods for assessing kidney function: cockcroft-gault and modification of diet in renal disease. Pharmacotherapy 2008;28:1125-32. 
59. Delanghe J, Speeckaert M. Creatinine determination according to Jaffe- what does it stand for? NDT Plus 2011;4:83-6.

60. Hudson JQ, Bean JR, Burger CF, et al. Estimated glomerular filtration rate leads to higher drug dose recommendations in the elderly compared with creatinine clearance. Int J Clin Pract 2015;69:313-20.

61. Péquignot R, Belmin J, Chauvelier $\mathrm{S}$, et al. Renal function in older hospital patients is more accurately estimated using the Cockcroft-Gault formula than the modification diet in renal disease formula. J Am Geriatr Soc 2009;57:1638-43.

62. Eppenga WL, Kramers C, Derijks HJ, et al. Individualizing pharmacotherapy in patients with renal impairment: the validity of the modification of diet in renal disease formula in specific patient with a glomerular filtration rate below $60 \mathrm{Ml} / \mathrm{Min}$. A Systematic Review. PLoS One 2015;10:e0116403.
63. Helldén A, Odar-Cederlöf I, Nilsson G, et al. Renal function estimations and dose recommendations for dabigatran, gabapentin and valaciclovir: a data simulation study focused on the elderly. $B M J$ Open 2013;3:e002686.

64. Maccallum PK, Mathur R, Hull SA, et al. Patient safety and estimation of renal function in patients prescribed new oral anticoagulants for stroke prevention in atrial fibrillation: a cross-sectional study. BMJ Open 2013;3:e003343.

65. Säwe J, Odar-Cederlöf I. Kinetics of morphine in patients with renal failure. Eur J Clin Pharmacol 1987;32:377-82.

66. Klimas R, Mikus G. Morphine-6-glucuronide is responsible for the analgesic effect after morphine administration: a quantitative review of morphine, morphine-6-glucuronide, and morphine-3-glucuronide. Br J Anaesth 2014;113:935-44. 